\title{
Design Strategy of Municipal Reconstruction of Expressway in Mountainous Area
}

\author{
Shang Ye* \\ China Merchants Chongqing Communications Technology Research \& Design Institute CO., LTD. Chongqing 400067, \\ China \\ *Corresponding author: Shang Ye, 317540110@qq.com

\begin{abstract}
The construction of a mountain expressway is critical to the development of the mountain economy and the creation of mountain areas. However, since the service life of many mountain expressways continues to increase, municipal transformation design is required to improve the smoothness of the expressway, make efficient use of space, and reduce resource waste. The author investigates the current challenges in the construction of a mountainous expressway and proposes an effective method for municipal reconstruction design of a mountainous expressway, in the hopes of assisting in the optimization and development of the mountainous expressway.
\end{abstract}

Keywords: Mountain area; Expressway; Municipal administration; Transformation design

Publication date: November 2021; Online publication: November 30, 2021

\section{Introduction}

In view of the actual situation of the construction of mountainous expressway at present, there are some problems such as traffic jam, road cutting and waste of land. In order to solve these problems, it is necessary to design the municipal transformation of mountainous expressway. At the same time, with the continuous expansion of the city, the original expressway construction area into urban area, also need to carry out municipal transformation, such as adding pipe network, lighting, etc. In this process, we must change the previous concept of highway design, accurately grasp the key points of highway municipal transformation design, in order to improve the quality of highway design, so as to better serve the construction and development of mountainous areas.

\section{Problems in the construction of mountainous expressway at present}

The service object of mountain expressway is usually people who need to travel for a long distance, which plays an important role in the communication between cities and the construction and development of cities. However, from the actual situation of expressway construction in mountainous areas at this stage, there are still some problems.

\subsection{Traffic congestion}

During the free passage of expressways on holidays, the traffic flow of expressways increases significantly, especially the increase of freight vehicles, which puts forward better requirements for the traffic capacity of expressways in mountainous areas and main lines of urban roads. With the continuous development and progress of mountain area and cities, the relationship between mountain area and cities has become closer. The construction of expressway not only undertakes the function of meeting the increase of internal traffic demand, but also needs to meet the external traffic demand. However, in the specific construction of 
mountainous expressway, due to the limitation of terrain, the distribution of interchange nodes is sparse, and the smooth traffic capacity of ramp is weak, which is prone to node congestion. In addition, with the expansion of the city, the functions of some expressways have changed and become urban expressways, which urgently need for its municipal transformation.

\subsection{The plots on both sides of the expressway are divided}

When laying some mountainous expressways, due to the limitation of terrain, the plots on both sides will be divided when setting expressway interchange nodes. On both sides of the expressway, only relatively low-grade roads can be used to connect the expressway through underpass. With the continuous development of mountain cities, the communication demand between cities is increasing. At this stage, there is a certain contradiction between the situation of mountainous expressways and the communication demand between cities. The problem of cutting land plots by mountain expressways is gradually highlighted.

\subsection{Waste of land resources}

On the one hand, expressways are usually laid by means of high embankments, which cover a large area, both the slope and the boundary cover a large area. On the other hand, toll stations are set at the entrances and exits of the expressway, which will cause certain restrictions on the setting of entrance and exit ramps and interchange conversion ramps. Therefore, most entrance and exit ramps and interchange conversion ramps adopt the form of trumpet interchange, which needs to occupy more land resources, and will obviously waste some land resources.

\section{Effective strategy of municipal reconstruction design of mountainous expressway}

\subsection{Change the previous ideas and ideas of expressway construction in mountainous areas}

In view of some problems existing in mountainous expressway at the present stage, we must actively change the previous design thoughts and ideas in the municipal transformation design.

First, in the municipal reconstruction of mountainous expressway, the dual system structure of the combination of main line and auxiliary line should be adopted to expand the capacity of main roads and expressways in mountainous cities. At the same time, each connecting node can be set up hierarchically, so as to solve the traffic congestion problem of the previous mountain expressway nodes and the whole.

Second, when designing the main road channel of expressway in mountainous area, it can be arranged by tunnel and viaduct. Auxiliary roads can be arranged in the form of composite channels on the ground, so as to maximize the use of land resources and avoid the waste of land resources.

Third, after completing the municipal design of expressway compound channel in mountainous areas, it is necessary to ensure that it forms a close road network structure with the surrounding roads, and ensure the refinement of the design, so as to improve the quality of expressway compound channel after reconstruction.

\subsection{Key points of municipal reconstruction design of expressway in mountainous area}

First, reconstruction design of expressway channel mode in mountainous area from the actual situation of highway network structure in mountainous areas at this stage, it cannot be well integrated with the overall urban road network ${ }^{[1]}$. The expressway channel designed after municipal transformation needs to become an important part of the urban road network structure, so as to share the functional requirements of urban internal traffic exchange and external long-distance fast driving. Combined with the actual development of cities along mountainous expressway, we should carry out municipal transformation design for different cities. The main manifestations are: On the one hand, for mountainous urban continuous areas, the 
composite highway mode combining expressway and trunk road can be used to reconstruct the expressway channel, so as to meet the long-distance traffic needs of cities along the expressway. On the other hand, for the undeveloped urban peripheral areas along the mountainous expressway, the municipal reconstruction design of the expressway channel in this area can be carried out through the mode of expressway and reserved main road, so as to meet the traffic needs of urban construction and development in this area at this stage and in the future.

Second, the municipal reconstruction design of highway channel scale in mountainous areas. By predicting and analyzing the traffic flow of the current urban road network structure in mountainous areas, the scale of the main road and auxiliary road of the composite channel of expressway in mountainous areas is defined, so as to better meet the traffic demand of dual system road network in mountainous cities.

Third, classify the nodes of mountainous expressway. Mountain expressway compound road is the intersection of different levels of roads ${ }^{[2]}$. In the process of municipal transformation design, effective communication between roads can be formed in the form of multi-level connection, so as to better meet the internal and external traffic needs of mountainous cities.

\subsection{Design optimization of municipal transformation of main line and interchange of mountain expressway}

In the process of municipal reconstruction design for the main road system laying of mountainous expressway at the present stage, the problem of resource waste can be solved by laying tunnels or elevated roads, cooperating with the ground laying of auxiliary roads, and making intensive use of the red line space of mountainous expressway ${ }^{[3]}$. At the same time, it is also necessary to optimize the "trumpet" interchange selected for the setting of toll stations, and dismantle the existing toll plaza. Combined with the traffic demand of mountainous cities at this stage, the original "trumpet" interchange is transformed into simple interchange and turbine interchange, which can save part of the area of the interchange and reduce the use of land resources through the economical arrangement of the interchange hub. Combined with the different turning requirements of expressway, the design standard and ramp direction of interchange ramp are optimized.

\subsection{Fine design of municipal transformation of mountain expressway}

In the process of improving the refinement of municipal reconstruction design of mountainous expressway, we should make full use of the saved land use. We can create a good mountainous expressway environment through landscape design on these land resources, so as to create a more beautiful expressway traffic environment for passing vehicles ${ }^{[4]}$. In addition, in the specific transformation design, we also need to pay attention to the setting of intelligent facilities, and use the setting of intelligent facilities to collect the operation of highway network in mountainous areas in real time, so as to provide greater convenience for people's travel. In addition, in the process of municipal reconstruction of mountainous expressway composite channel, the function of urban trunk road can be shared through the reconstruction of auxiliary road system. At the same time, in the concrete process of municipal reconstruction design of mountainous expressway, it is also necessary to fully embody the concept of people-oriented transformation, in order to meet the needs of people's long-distance and fast travel as the main starting point, as far as possible to improve the spatial quality of mountainous expressway, so as to create a good quality expressway environment for the masses.

\section{Conclusion}

To summarize, the goal of the municipal reconstruction design of a hilly expressway is to change the expressway's attribute and turn it into a municipal road. In order to carry out the specific reconstruction 
design more reasonably, it is not only necessary to analyze the current operation of the mountain expressway to identify existing problems, but it is also necessary to comprehensively analyze the traffic functions and traffic demand of the mountain expressway in the future. Simultaneously, in the process of reconstruction design, it is also necessary to clarify the scale of the expressway channel and the level of each traffic conversion node in accordance with the focus of municipal expressway reconstruction in mountainous areas, solve the problem of highway overall and node congestion through the channel mode of combining trunk road and auxiliary road, save land resources, and improve the spatial reconstruction quality of expressways.

\section{Disclosure statement}

The author declares no conflict of interest.

\section{References}

[1] Yang LT, 2020, Route Selection and Construction Management Measures for Expressway Construction in Mountainous Areas. Construction \& Design for Project, (13): 95-96 + 99.

[2] Gong JY, Chen SH, Zhang X, 2020, Discussion on Route and Construction Management Measures for Expressway Construction in Mountainous Areas. China Collective Economy, (01): 160-161.

[3] Huang Y, 2018, Analysis and Improvement Countermeasures of Expressway Traffic Safety in Southwest Mountainous Area. Chan'an University.

[4] Han XD, Li ZJ, 2017, Analysis on the Selection and Rotes Design of Highway in Mountainous Areas. Engineering and Technological Research, (06): 205-206. 